\section{Commentary: How can we improve minimally invasive surgical ablation of atrial fibrillation?}

\author{
Leonid Sternik, MD
}

I enjoyed reading the article by $\mathrm{Li}$ and colleagues ${ }^{1}$ reporting on 77 patients operated on with lone atrial fibrillation (AF). All patients underwent thoracoscopic AF ablation and left atrial appendage closure. I am sure that surgeons can efficiently and safely help many patients with lone AF. My criticism of this study is that ablation was insufficiently effective. All patients were in paroxysmal AF before ablation. The median AF history was 2 years. Left atria were not enlarged much, with diameters $<39 \mathrm{~mm}$. After a median follow-up of 951 days, only 52 patients $(67.5 \%)$ remained in sinus rhythm. I would expect in an "easy" group of patients to see approximately $90 \%$ sinus rhythm after surgical ablation. Surgeons attempting to use a minimally invasive approach may perform less effective ablation. In most minimally invasive approaches, off-pump epicardial ablation with a monopolar device or bipolar epicardial pulmonary vein isolation is performed. It is clear that with blood flowing in the left atrium, it is very difficult to cause thermal damage to the endocardial layer with transmural scar formation. Miyagi and colleagues ${ }^{2}$ reported that epicardial monopolar radiofrequency ablation does not produce a transmural lesion and a conduction block. Pruitt and colleagues $^{3}$ found that only $42 \%$ of patients were in sinus rhythm after microwave epicardial ablation.

\footnotetext{
From the Department of Cardiac Surgery, Sheba Medical Center, Tel-Hashomer, Israel.

Disclosures: The author reported no conflicts of interest.

The Journal policy requires editors and reviewers to disclose conflicts of interest and to decline handling or reviewing manuscripts for which they may have a conflict of interest. The editors and reviewers of this article have no conflicts of interest.

Received for publication March 16, 2021; revisions received March 16, 2021; accepted for publication March 18, 2021; available ahead of print March 23, 2021. Address for reprints: Leonid Sternik, MD, Department of Cardiac Surgery, Sheba Medical Center, Tel-Hashomer, Israel 52621 (E-mail: Leonid.sternik@sheba. health.dov.il).

J Thorac Cardiovasc Surg 2023;165:1395-6 0022-5223/\$36.00

Copyright (C) 2021 Published by Elsevier Inc. on behalf of The American Association for Thoracic Surgery

https://doi.org/10.1016/j.jtcvs.2021.03.062
}

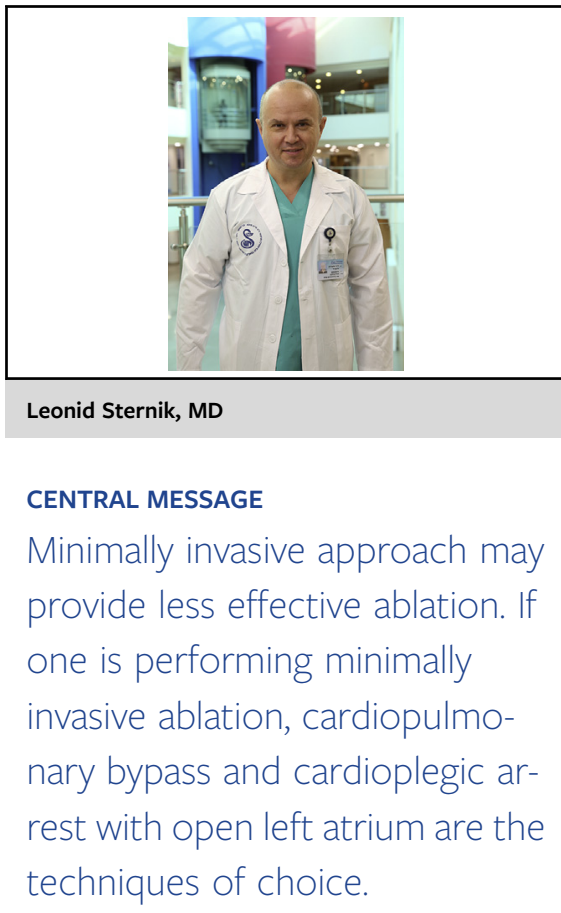

I feel that all monopolar off pump epicardial ablations are insufficiently effective. ${ }^{2-5}$ Bipolar epicardial pulmonary vein isolation might not be transmural. Left atrial wall thickness could reach 4 to $5 \mathrm{~mm}$. When applying the bipolar ablator epicardially, we clamp 2 layers of atrial wall and might not achieve transmurality, especially offpump. That is why we proposed a technique of box lesion in the open left atrium ablating only one atrial wall. ${ }^{6}$

$\mathrm{Li}$ and colleagues experienced no procedural complications with thoracoscopic ablation. That is not the case in many institutions. In a very recent multicenter randomized controlled trial from Great Britain, Haldar and colleagues ${ }^{7}$ compared catheter ablation and thoracoscopic surgical ablation of AF and found that thoracoscopic surgical ablation was not superior to catheter ablation in establishing and maintaining normal sinus rhythm. The authors reported numerous operative complications in the thoracoscopic surgical ablation group of 55 patients. One patient died, 2 patients had phrenic nerve injury, and 2 patients had surgical site infection. I am sure that a standard open heart surgery with cardiopulmonary bypass in these patients at very low surgical risk can be absolutely uncomplicated in the vast majority of cases. If one is interested in performing minimally invasive surgical ablation using mini-thoracothomy or thoracosopy, I think it should be performed with 
cardiopulmonary bypass and cardioplegic arrest with an open left atrium.

It is clear that surgical ablation of lone atrial fibrillation can help many patients, and the minimally invasive approach seems to be attractive. But of course, most important are the results and patient safety. If we achieve excellent results, much better than catheter ablation results with uneventful and safe surgery, we will have a lot of referrals for surgery and help many patients.

\section{References}

1. Li X, Li M, Shao Y, Gu W, Ni B, Gu J, et al. Thoracoscopic ablation delays progression from paroxysmal to persistent atrial fibrillation. J Thorac Cardiovasc Surg. 2023;165:1387-94.
2. Miyagi Y, Ishii Y, Nitta T, Ochi M, Shimizu K. Electrophysiological and histological assessment of transmurality after epicardial ablation using unipolar radiofrequency energy. J Card Surg. 2009;24:34-40.

3. Pruitt JC, Lazzara RR, Ebra G. Minimally invasive surgical ablation of atrial fibrillation: the thoracoscopic box lesion approach. J Interv Card Electrophysiol. 2007; 20:83-7.

4. Melby SJ, Zierer A, Kaiser SP, Schuessler RB, Damiano RJ Jr. Epicardial microwave ablation on the beating heart for atrial fibrillation: the dependency of lesion depth on cardiac output. J Thorac Cardiovasc Surg. 2006;132:355-60.

5. McCarthy PM, Kruse J, Shalli S, Ilkhanoff L, Goldberger JJ, Kadish AH, et al. Where does atrial fibrillation surgery fail? Implications for increasing effectiveness of ablation. J Thorac Cardiovasc Surg. 2010;139:860-7.

6. Sternik L, Kogan A, Luria D, Gilkson M, Malachy A, Levin S, et al. Box lesion in the open left atrium for surgical ablation of atrial fibrillation. J Thorac Cardiovasc Surg. 2014;147:956-9.

7. Haldar S, Khan HR, Boyalla V, Kralj-Hans I, Jones S, Lord J, et al. Catheter ablation vs. thoracoscopic surgical ablation in long-standing persistent atrial fibrillation: CASA-AF randomized controlled trial. Eur Heart J. 2020;41:4471-80.
Commentary: What is the measure of success for atrial fibrillation ablation? Is a reduction in arrhythmia burden sufficient?

\author{
James R. Edgerton, MD, ${ }^{\mathrm{a}, \mathrm{b}}$ and \\ Ralph J. Damiano, Jr, MD
}

In this issue of the Journal, $\mathrm{Li}$ and colleagues ${ }^{1}$ follow a small cohort of patients with paroxysmal atrial fibrillation (PAF) and previous cerebrovascular or peripheral thromboembolism, without previous intervention, who underwent stand-alone thoracoscopic pulmonary vein isolation and left atrial appendage excision. They compared these patients with a smaller group who opted for medical management. After controlling for $\mathrm{CHA}_{2} \mathrm{DS}_{2}$-VASc score (ie,

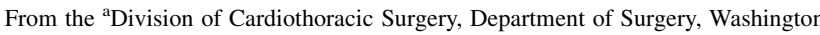
University School of Medicine, Barnes-Jewish Hospital, St Louis, Mo; and ${ }^{\mathrm{b}}$ Baylor Research Institute, Dallas, Tex.

Disclosures: J.R.E. reported speaker for AtriCure, Inc. R.J.D. reported speaker and research funding from AtriCure, Inc, and consultant, Medtronic.

The Journal policy requires editors and reviewers to disclose conflicts of interest and to decline handling or reviewing manuscripts for which they may have a conflict of interest. The editors and reviewers of this article have no conflicts of interest.

Received for publication April 1, 2021; revisions received April 1, 2021; accepted for publication April 5, 2021; available ahead of print April 20, 2021.

Address for reprints: James R. Edgerton, MD, Division of Cardiothoracic Surgery, Department of Surgery, Washington University School of Medicine, BarnesJewish Hospital, St Louis, Missouri Campus Box 8234, 660 S Euclid Ave, St Louis, MO 63110 (E-mail: james.e@email.wustl.edu).

J Thorac Cardiovasc Surg 2023;165:1396-7

$0022-5223 / \$ 36.00$

Copyright (c) 2021 by The American Association for Thoracic Surgery

https://doi.org/10.1016/j.jtcvs.2021.04.015

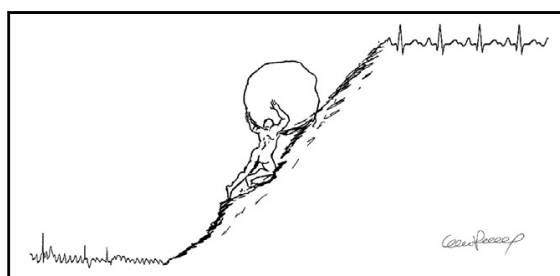

Sisyphus: Is success how often he makes it to the top or how far he climbs each time?

CENTRAL MESSAGE

The way we monitor for atrial fibrillation is changing to intermittent rhythm strips, which will yield determinations of burden. Physicians will need to determine new definitions of success.

congestive heart failure; hypertension; age $\geq 75$ years; diabetes mellitus, stroke, or transient ischemic attack; vascular disease; age 65-74 years; sex category), the authors found that pulmonary vein isolation delayed progression of PAF.

This study has serious limitations, hindering applicability. The control group comprised patients who refused surgery and therefore were not equivalent controls. The study group did not meet indications for stand-alone ablation, as they were not refractory to drug therapy and had 